\title{
WHAT IS A SPECIES? 1
}

\author{
PROFESSOR S. W. WILLISTON
}

\section{University of Chicago}

$W_{E}$ have had in the past not a few interesting discussions upon or controversies over the methods of evolution and the origin of species in this club. We have more or less plausible theories as to the evolution of species, by natural selection, mutation, inheritance of acquired characters, etc., but we have very nebulous ideas as to what species really are. Nothing is more common than the term species; nothing is more uncertain than what species are.

Long after the present topic had been suggested for discussion by the club, I was delighted to learn of a like discussion to be held at the late meeting of the Botanical Society in Chicago. I anticipated that symposium with the liveliest feelings of satisfaction, confidently expecting a brilliant illumination of the whole umbrageous subject, an effulgence of light that would throw into deepest obscurity whatever feeble beams I might myself hope later to cast upon it. But lamentable was my disappointment. I heard some ancient platitudes that the zoologists ceased in despair to consider a dozen years agone, and many anathemas showered upon the botanical taxonomist. They berated him for making such a mess of classification, and hinted very freely that he didn't know much anyhow, and probably never would. If all that was said be true, then indeed the botanical taxonomists are a sorry lot. One distinguished speaker declared they had made no progress since the time of Linné, and he rather seemed to desire that the whole tribe might be banished to some desert isle where there is neither vegetable life nor printer's ink, that they might no longer trouble the ecolo-

${ }^{1}$ A paper read before the Biological Club of the University of Chicago. 
gists and physiologists, et $i d$ genus omne. But I can not escape a harrowing doubt as to what the learned speakers' vocations in botany would be, if the maligned taxonomists had not got in their diabolical work. Possibly they would distribute an herbarium with each lucubration, that their readers might know what they were writing about; or possibly they might undertake to name their own species, for I have seldom known the morphologists to escape the mihi itch on very slight infection.

I sympathize with the physiologist or ecologist, who after he has written a luminous paper on a Cratægus or Viola, or Rosa, or Opuntia, endeavors to ascertain the proper name for his plant; but I do not sympathize with his objurgations against the whole tribe of species makers. There is a deal of pseudo science, unripe science-were it not undignified I would characterize some of it by an expressive monosyllabic word suggesting decomposition - published about species by the taxonomists, but I suspect that there is also a large deal of like obnoxious material lying at the doors of the physiologists and ecologists and morphologists. But that fact does not make taxonomy or ecology anything less of a science, nor the work of able men in either less valuable. I am a little weary of hearing from narrow specialists in other departments of biology constant condemnation of the taxonomist, and I have been hearing such for the past fifteen years from men who should know better.

Now, as one who has been guilty in the past twenty-five years, let me say it humbly, of naming and attempting to describe ten or twelve hundred so-called species and genera, I beg leave to make a few remarks about species. You may properly accuse me of being one of those degenerates the taxonomists and, as his tribe is not well represented here to-night, I may be permitted to present his side of the case. I hold no brief for the criminals, but, as one of the accused, I would present my own defense and my own views.

The question, What is a species? has been asked re- 
peatedly, I may say continuously, since the time of Linné, even if our friends the botanists have been somewhat somnolent of late. We have had no satisfactory answer, for the simple and very good reason that there is none, and never will be. If we could go back to the happy Cuvierian or even Agassizian days and throw the whole responsibility of their definition upon the Creator, seeking some revelation in Holy Writ, it would save us much useless worry. But, as we have long since learned that species, like Topsy, just grew, we have and always shall have as great difficulty in deciding when varieties and races become species as we have in determining when a puppy becomes a dog or a lamb a sheep.

Let me premise further with the statement that true taxonomy is the most advanced and difficult of all biological science. O modest claim is it not? But I think that you will readily admit that evolution, as a science, is the highest end of biology - and taxonomy is merely the graphical expression of evolution. If, then, we do sometimes baptize a score of hawthorns, or bedbugs, or coyotes, where the breeder or ecologist thinks that he finds but one later, we crave your sympathy and your aid, not your scorn and contumely. The breeder may get all variations between the domestic ox and the American bison, and they will breed reasonably true by artificial selection, but the assertion that Bos americamus and Bos taurus are one and the same species would be preposterous. Is it not possible that some of our learned breeders of plants and animals may be in error themselves in their views of "species"?

All classificatory terms are impossible of exact definition. Their use always has and always will depend upon the consensus of opinion of those best qualified by wisdom, experience and natural good sense. They will never become stable; we shall never cease to amend, to change, to repudiate old and propose new, because we shall never reach the final summation of science. We can only hope that all changes shall be for the better, shall be nearer the 
real truth; that incompetent and inexperienced taxonomists shall be ruled out of court, even as incompetent anatomists and cytologists are disbarred. The unfortunate thing is that we taxonomists have so bound ourselves in a snarl of laws and by-laws that we are compelled to incubate and wet-nurse every premature and monstrous taxonomical imbecility till it dies a natural death, whereas those of other biologists are promptly strangled or thrown out into the cold to die of inanition. Let us hope that we may escape from some of that snarl, or at least that we may cut some of the bonds which hold us too tightly.

To discuss our subject in all its details and bearings and from all view-points would require, not one evening, but many. Permit me, therefore, to offer for your consideration certain axioms of evolution-theories or hypotheses if you prefer to call them such-bearing more or less closely upon the question, What is a species? Some or all may be familiar to you-I do not know whether all have beeen in print or not-but, such as they are, they are all based upon my own observation, and, so far as that goes, I am prepared to defend them, and will endeavor to do so later if there are any you repudiate, as perhaps there are.

1. The only biological entity is the individual, and the individual is inconstant.

2. The value of specific characters is dependent upon a number of interrelated and inseparable factors, the chief of which are environment and heredity.

3. Accumulated heredity may outweigh natural selection or environment, and vice versa.

4. A crescent phylum is more variable, more plastic than a long established one; that is, time is always an element in the fixation of characters and the limitation of variation, and the length of time is dependent more or less upon the strenuousness of environment and selection, and the plasticity of the type.

5. New phyla arise from crescent phyla, never from decadent or even dominant ones. 
6. The decadent phylum may present as unstable saltations, generic or even higher characters of allied dominant groups ; that is a character of generic or even family value in a dominant group may be merely an individual variation in a decadent one.

7. The members of a dominant group are, ceteris paribus, more closely adapted to their environment, their characters less variable, their geographical distribution more restricted. That is, species of dominant groups may be safely based upon less distinctive characters than those of a crescent phylum.

8. It follows that senility and decadence are the attributes of species, families and orders, as well as of the individual.

9. The older the genus or allied group of species, the more restricted, apparently, is fertile hybridity. For example: The genus Rhinoceros is an old one that has been but little modified since early Miocene times; I have never learned of cases of hybridity between living species. Equus arose in early Pliocene times with all its essential modern characters; hybridization between all its living species is not difficult, but the hybrids are infertile. The genus Bos, while beginning in the Pliocene, did not attain full development till Pleistocene times; its numerous species are continuously fertile in all combinations. Rhinoceros is long past the zenith of its evolution; its highest specialization was in the Pliocene, or at most Pleistocene. Equus, too, is past the highest point of its development, perhaps, but not far. Bos, on the other hand, is a dominant or crescent type; its maximum specialization is in the present time.

10. Secondary sexual characters are transmitted to the opposite sex, unless of positive disadvantage. Varietal and specific characters, in the natural course of events, are more or less unisexual at their inception, and the constant tendency is for the characters of one parent to be transmitted to offspring of both sexes, even when such characters are apparently useless, as seen in the rudj- 
mentary mammæ of the human male, which, indeed, sometimes become of functional use.

11. Secondary sexual characters are more numerous and less stable in the male than in the female; that is, female sexual characters, whether primary or secondary, may be of generic or even family value in groups wherein like characters in the male are merely specific or even individual. I am aware that some modern naturalists would discredit sexual selection, but, until some hypothesis is given to replace it, I must still continue to believe that sexual selection is necessary to account for secondary sexual characters.

12. An organ once functionally lost is never permanently regained by natural selection or any of its hypothetical substitutes. A hexadactyl species of Homo or Felis is impossible.

13. Giantism in any group is an indication of approaching decadence; giants never give origin to dominant phyla of smaller average size.

To these I may add, as an article of faith, one more:

14. Fertility depends chiefly upon the inheritance of physiological characters. A modification in the behavior of the sperm and germ cells may affect fertility even before structural characters have become much affected, and vice versa. Human males and females, as we all know, are sometimes infertile with each other, though each may be entirely fertile with some other; an extension of this infertility to races would produce what the taxonomist would accept as species. I furthermore believe that the accumulated inheritance of physiological characters may and does produce determinate lines of evolution, that is, orthogenesis, which may go on into hypergenesis, if I may use this term to indicate that hereditary momentum which results in over-development of organs. I account for this accumulated heredity by the action of past environment upon the organism, that is, Lamarckism. I am also quite aware that $I$ am with the minority in the acceptance of Lamarckism as the chief causative prin- 
ciple of the origin of species. I am told that the direct effect of environment in modifying germ characters can not be proven, and I retort, neither can it be disproven. Paleontologists almost universally, and taxonomists generally, are Lamarckians, that is, those who deal chiefly with range and distribution, time and space; laboratory biologists, on the other hand, are almost invariably opposed to the theory of the transmissibility of acquired characters. We can see no alternative hypothesis that will meet the requirements of the classificationist or the paleontologist, and we respectfully submit that the experiments of a few years or even scores of years are trivial in comparison with the natural experiments that go on through tens of thousands of years in the origin and fixation of species. From my little water-garden some years ago I took some plants of the common water hyacinth and planted them in the ground. I was surprised to find that they grew luxuriantly, but that they did not develop the peculiar bladder-like swelling of the leaf stems; when I again transferred some small offshoots to the water, they promptly redeveloped them. The plants immediately changed their structure in adaptation to their terrestrial or aquatic environments, and doubtless they would do so after many years of isolation. But had the water hyacinth been cultivated as a garden plant in the soil since the time of Pliny I believe that the terrestrial character would have become fixed, and, after all, two or three thousand years is a very short time in the history of plant species. The Weismannians have been compelled to recede a long way from their first position of the absolute and eternal distinction between germ-plasm and bodyplasm; perhaps we shall yet find an intermediate place that will satisfy us all.

In claiming a high degree of importance for physiological characters and physiological isolation in the formation and preservation of species I need not say that the term physiological is merely a confession of ignorance. All physiological function must inevitably depend ulti- 
mately upon structure. Two cells absolutely alike must doubtless function quite alike. But I doubt if there ever are any two cells quite alike. We are already learning, if I am correct in my understanding of the claims of McClung and others, that even minor, so-called specific differences are discoverable in the cell, in some groups at least. There is, of course, no such thing as a purely physiological species, for changed structure must underlie all variation, though we may not be able to discover the differences. I can conceive that additional or modified chromosomes in the germ cells of the greyhound might indicate a partial physiological isolation which has preserved this race of dogs almost undefiled through more than three thousand years; certainly man has not been the cause of its preservation.

Now, if the foregoing theses or hypotheses be true, or even if the greater part of them be fundamental principles of variation, it follows that the definition of species must be made for each and every one that exists or has existed; that a specific character in one group may be merely varietal in an allied group, on one hand, or generic in another, on the other hand. Or, aphoristically, every species, as we know to be the case with every genus, is a law unto itself. And this is, practically, the working rule of every competent taxonomist, though of course many sad errors are made in its application. And it follows that he who is best qualified to propose and name species, or to criticize those which have been proposed by others, is one whose acquaintance is widest with living forms and with the laws which underlie their evolution. He must not confound genetic with adaptive character's, for phylogeny is the sole end of taxonomy.

Since we can not give an answer to the question, What is a species? let us analyze briefly some definitions of the past:

1. A species is a form of life which breeds true to itself. The Jewish race has bred true to itself, as indicated by its distinctive physiognomy, since the time of Rameses; and 
the Bourbon nose is characteristic of that family. Ergo, the Jews and the Bonapartes are distinct species of Homo!

2. True species are incapable of fertile hybridity. The example of the Catalo, the fertile hybrid between Bos americanus and Bos taurus, will suffice. The domestic dog interbreeds freely on the plains with the coyote, and no one doubts the specific validity of Canis latrans, whatever we may think about coyotes in general. The domestic cat, according to Pocock, is a hybrid between the wild cat of England and the wild cat of Egypt, with a distinct tendency to vary along ancestral lines after centuries of fertile hybridity. The domestic races of dog freely interbreed, and yet we are quite sure they are the derivatives of 'several wild species of Canis. May not fertility, as a physiological inheritance, account for the preservation of their distinctive types, notwithstanding man's artificial selection? Is it probable, for instance, that the Boston terrier hybrid will continue longer than the fad of its breeding remains undiminished?

3. A species is a type which varies only within narrow limits. The jungle fowl is fairly constant in nature. Its extraordinary variability is seen in the domestic fowls, whether they be derived from a single or several wild species. And the doves are still better examples. A turkey and guinea-fowl, on the other hand, though they have been domesticated for centuries, vary but little from their ancestral types.

There are other definitions. But, you say, if I accept no definition of species what rules do the taxonomists have who "make" so many thousands of them? We must have some, and we do have them, even if we are so often accused of depending on whim and imagination. And these are mine: Forms of animals which present distinct assemblages of characters, in form, color and arrangements of parts under natural conditions, which are recognizable from descriptions and figures, should receive distinctive names and be catalogued, provided, of course that the assemblage of characters includes all onto- 
genetic changes. If, in the examination of abundant material from different natural environments, we find these characters fairly constant, the forms may properly be called species; if not, varieties or races. No perfect specific description can be drawn from a single specimen or from a few even, and the skill of the taxonomist is conspicuously shown in his ability to distinguish between variable and fixed characters, between the essential and non-essential, in other words, between old and new characters. Some taxonomists-and I know such-remain, after many years' experience, unable to dissociate individual from specific or generic characters; they describe species as they would describe the physical features of a tree or of a rock-and they are the ones who deserve the condemnation of other workers. Are such workers confined exclusively to our branch of biology?

In nature the interrelated factors, of which environment and heredity are the chief, are normally in a state of substable equilibrium - variations within given groups are within certain fairly. definite limits, because the factors of variation are. If, however, the cumulation of any one factor, either naturally or artificially, occurs, the variations become inconstant and the limits of variation are changed. The wild pigeon in nature, for instance, is governed by fairly constant conditions, and its variations are small. Its domestic varieties, were they existent in nature, would not interbreed, and would be good species. Breeders, I think, lose sight of such things when they say, as some do, that they can produce specific characters, that is, characters which are deemed of specific value by taxonomists. They can do nothing of the sort. You may break down by changed environments and artificial selection what would be real specific characters under natural selection and natural environment, but you do not make species thereby. Time and fixation by heredity, I believe, must always be taken into account in determining varietal, specific or generic characters. Mutations of Enothera lamarckiana were found growing wild by de Vries, es- 
caped from some garden. Under cultivation he continued to breed them, and produced others. But his plants were all under abnormal environments. Dr. Lutz, whom we all know, is doing some exceedingly interesting experiments upon certain small flies, Drosophila ampelophila. He has produced some remarkable sports or "mutations," and the surprising thing is that he finds that such sports breed true, that there is an apparent loss of fertility between them and the normal forms. But I think it is absolutely certain - and I speak as an entomologist fairly familiar with flies - that it would be impossible to produce species of his sports, even though they were bred for a thousand years. As some of us know, polydactyl cats are rather abundant in some parts of Connecticut, breeding true-but who believes in a species of six-toed cats? It is rather unfortunate that breeders confine their attention almost exclusively to plastic forms, that is, to geologically recent types. Let some one try experiments with archaic forms and watch the results.

Experimental breeding and ecology are the two fields of biological research which promise most at present; they will doubtless contribute not a little to our knowledge of the methods of evolution, and correct not a few errors in taxonomy; but I say, with full deliberation, that experimental breeding without a wide knowledge of taxonomy will lead to false conclusions and be comparatively barren of results. The experimentalist, of all men, must be well acquainted with varietal specific and generic characters in the groups which he studies, or he will be working blindly. And I am sorry also to say that some of the severest criticisms of taxonomists and taxonomy have come from some of these men. 